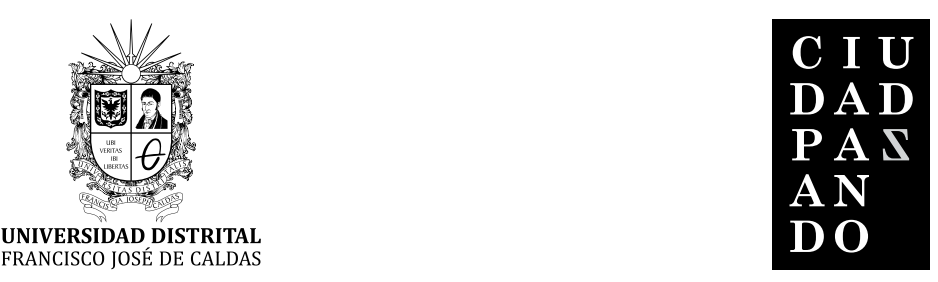

DOSSIER

Artículo de revisión

\title{
Coragyps sapiens: una propuesta de revitalización y reconstrucción simbólica del cuerpo social desde el teatro
}

Coragyps sapiens: a proposal for the symbolic reconstruction of the social body from the theatre

Coragiyps sapiens: uma proposta de revitalização e reconstrução simbólica do corpo social do teatro

\section{Sandra María Ortega Garzón ${ }^{1}$}

Para citar: Ortega, S. (2018). Coragyps sapiens: una propuesta de revitalización y reconstrucción simbólica del cuerpo social desde el teatro. Revista Ciudad Paz-ando, 11(1), pp. 16-24. doi: https://doi.org/10.14483/2422278X.13045

Fecha de recepción: 22 de febrero de 2018

Fecha de aprobación: 17 de abril de 2018

1 Estudiante del Doctorado en Lengua y Literatura Catalana y Estudios Teatrales, Universidad Autónoma de Barcelona. Docente de planta, Universidad Distrital Francisco José de Caldas. Correo electrónico: samaortega@gmail.com 


\section{RESUMEN}

Coragyps sapiens es el nombre de la obra dramática de Felipe Vergara escrita en 2013. En ella, el autor no solamente representa la violencia ejercida sobre el cuerpo durante el conflicto armado en Colombia, sino que plantea, a manera de metáfora, una propuesta para la reconstrucción social en el país. El presente artículo discute dicha propuesta mediante el análisis de las imágenes presentes en el texto y desentraña el lenguaje metafórico para entender sus posibles alcances; de esta forma, se pretende destacar el papel del arte dramático como creador de acciones que viabilizan la reconstrucción simbólica del tejido social en un país fracturado por la violencia y, sin embargo, empeñado en el establecimiento de una paz duradera.

Palabras clave: representación, teatro, mito, reconstrucción social, posconflicto, paz.

Coragyps Sapiens is the name of Felipe Vergara's dramatic play written in 2013. In this work the author represents not only the violence triggered over the victim's body during the Armed Conflict in Colombia, but also puts forward, as a metaphor, a proposal for the social reconstruction in the country. This article discusses the above-mentioned proposal through the analysis of the images inside the text and studies the metaphorical language to understand its possible implications. Hereby the article tries to emphasize the role of the dramatic art as a creator of actions that make viable the symbolic reconstruction of the social fabric in a country fractured by violence, and, nevertheless, committed to establish a lasting peace.

Keywords: imaginary representation, drama, myth, social reconstruction, post-conflict, peace.
Coragyps Sapiens é o nome da obra dramática de Felipe Vergara escrita em 2013. Nesta obra o autor não representa só a violência exercida sobre o corpo durante o Conflito Armado na Colômbia, mas também coloca, como metáfora, uma proposta para a reconstrução social no pais. Este artigo discute dita proposta através da análise das imagens presentes no texto e desvenda a linguagem metafórica para entender seus possíveis alcances. Desta forma, pretende se destacar o papel da arte dramática como criadora de ações que viabilizam a reconstrução simbólica do tecido social em um pais fraturado pela violência e no entanto, comprometido com o estabelecimento de uma paz duradoura.

Palavras-chave: representação- teatro- mito, reconstrução social, posconflito, paz. 


\section{Introducción}

Coragyps Sapiens de Felipe Vergara (2013) es una obra dramática que aborda el estado de la sociedad colombiana durante los escabrosos y penosos sucesos del conflicto armado, lo hace a partir de "un animal-personaje: el zopilote, que se erige en un símbolo totémico a través del cual la muerte se transforma en vida y en amor" (Lamus, 2013, p. 19). Sus protagonistas son una especie de hombres-zopilotes, Ulpiano y Reina. Ulpiano, es un campesino que se ha apartado de la comunidad, se ha exiliado en un islote dentro de lo que sería su propiedad, un islote rodeado por el agua de uno de los ríos más tenebrosos de la literatura colombiana, uno que representa a todos los otros (Sinú, San Jorge, Cauca, Magdalena, Catatumbo, Atrato y San Juan) que acogieron los muertos de la guerra, los llamados muertos de agua. Él ha decidido por convicción propia emprender una labor que nadie desea o nadie se ha propuesto hacer: ayudar a los zopilotes a limpiar el mundo de la muerte que se amontona en su territorio.

Esta creación dramática aborda fundamentalmente dos problemáticas, una de país y otra existencial: la primera, el fenómeno de las masacres producto del conflicto armado colombiano y, la segunda, la condición del hombre y la sociedad colombiana. La primera problemática, el escandaloso número de muertos a causa de las masacres y la absurda práctica de arrojar el "cadáver al agua y borrar todo rastro de su existencia" (Rodríguez, 2015, p. 52), una de las violencias más dolorosas en el país en las décadas anteriores a la creación de la obra en 2013. Durante este periodo, "las víctimas fueron ignoradas tras los discursos legitimadores de la guerra, fueron vagamente reconocidas bajo el rótulo genérico de la población civil o, peor aún, bajo el descriptor peyorativo de 'daños colaterales'” (Centro Nacional de Memoria Histórica, 2013, p. 14). Sin embargo, el anonimato de las víctimas pasó a ser un tema neurálgico a partir de la creación de la Ley de víctimas en 2011, de los inicios de los diálogos de paz en 2012 y la divulgación de iniciativas comunitarias como la práctica de adopción de los muertos anónimos en Puerto Berrío y otras poblaciones ribereñas.

En relación con la segunda problemática, la de la situación de la sociedad colombiana, se hace obvio que las discusiones de la obra se dirigen al resquebrajamiento de los tejidos sociales en todo el territorio nacional y, en especial, en las comunidades campesinas, víctimas mayoritarias del conflicto. Comunidades que, regidas anteriormente por leyes ancestrales de armonía y reciprocidad, experimentaron a través de los años cómo la violencia les fue robando todo su legado simbólico de pertenencia y comunión para implantar el miedo, el individualismo y las barreras entre uno y otro; entre ellas, un lenguaje de otredad que creaba grietas insalvables entre quienes antes eran conocidos, amigos, familiares y vecinos. El discurso de unión fue sustituido por el del miedo y la defensa individual. El "yo" suplantó estruendosamente al "nosotros".
De cara al anterior panorama de desestructuración social y la necesidad naciente de la comunidad de hacer algo con la muerte anónima, el autor se interroga sobre la muerte y sobre su materialidad, expresa que ante tal situación sintió que "no íbamos a avanzar hacia ningún lado a menos que no enfrentáramos esa materialidad de la muerte como sociedad [...] entonces quería hablar de eso, de la materialidad de la muerte, de una posibilidad de generar cambio" (Vergara, 2018); así, ante la inquietud de Vergara por la generación de un cambio aparece una pregunta: ¿El arte dramático puede contribuir a la reconstrucción del tejido social en un país desmembrado por la violencia?, ¿de qué forma?

Para responder tal interrogante, este artículo examina la obra Coragyps sapiens como una gran metáfora que representa la situación caótica del país y, al mismo tiempo, vislumbra una salida. Para esto se toman algunas herramientas del mitoanálisis ${ }^{2}$ y se estructura el escrito en cuatro partes: la primera parte examina la imagen del cuerpo animal como forma de representación del estado de la sociedad colombiana, la segunda revela el componente simbólico de lo animal en la obra y expone cómo el zopilote se convierte en una figura de revitalización social, la tercera estudia la metáfora animal del Coragyps sapiens como una forma de alianza humano animal que subraya la necesidad de transformación del hombre y la sociedad, la cuarta descubre el mito detrás de la obra con el fin de ocuparse de la propuesta lanzada por Vergara para la reconstrucción simbólica del cuerpo social.

\section{El cuerpo animal como escritura de una sociedad fragmentada}

El animal como figura de representación ha sido usado mayoritariamente como imagen de un panorama dicotómico, lo humano y lo inhumano, hombre y animal, civilizado y salvaje, o como imaginario de otredad: el 'otro' (animal) que puede devorar, que representa un amenaza personal o social, que es diferente o que es inferior, insignificante. La "cuestión animal", en ese sentido, ha servido para reflexionar acerca de la vida y del sujeto, especialmente acerca del poder sobre la vida; por ello, los discursos de diferentes pensadores, entre ellos, Giorgio Agamben (2006), Jacques Derrida (2008) y Gabriel Giorgi (2014) discurren en torno a lo animal y a la problemática ético-política "que conlleva la posibilidad de dominar de disponer de la vida - de aquellos seres identificados como 'otro' en la hoy ya evidente línea que va desde el animal a la mujer o al judío" (Fleisner, 2010, p. 249).

\footnotetext{
2 La metodología del mitoanálisis propuesta por Durand (2003) consiste en descubrir cuáles son los mitos patentes o latentes que atraviesan o sustentan un determinado momento histórico-cultural para poder leer a través de estos el pensamiento o corrientes de pensamientos presentes en dicho tiempo.
} 
Agamben (2006), por ejemplo, explica en Lo abierto la existencia de una máquina antropológica que funciona "excluyendo de sí como no (todavía) humano un ya humano, esto es, animalizando lo humano, aislando lo no-humano en el hombre" (p. 75), y de la cual se derivan figuras como la del judío, "el no-hombre producido en el hombre, o el néomort y el ultra-comatoso, esto es, el animal aislado en el mismo cuerpo humano" (p. 75). Esta exclusión lo que parece producir es un espacio abierto, una especie de eslabón perdido entre el animal y el hombre, no "una vida animal ni una vida humana, sino sólo una vida separada y excluida de sí misma, tan sólo una vida desnuda" (p. 76); así, de la misma forma en que el judío es lanzado a este espacio de exclusión, muchos otros reciben la misma suerte, ya sea por cuestiones de origen, raza, clase, religión, pensamiento y otro buen número de alteridades.

Bajo este panorama se crean categorías como el "viviente", la vida reducida a máquina biológica; la zoé (vida biológica) separada del bios (vida calificada, apropiada); la "persona" desprendida de la "no persona", lo que expone una reducción de la vida del hombre y una contigüidad con la vida animal. La anterior categorización da paso a la diferencia entre un cuerpo valioso y reconocido políticamente y uno sacrificable o desechable, de allí a la figura del cuerpo animal, que "será la zona de indeterminación sobre la que se trazará esa distinción que, inevitablemente, permanecerá inestable, difusa y, por lo tanto, crítica, en la medida en que revoca todo ordenamiento fijo de cuerpos" (Giorgi, 2014, p. 138).

El cuerpo animal es la figura presente constantemente en la obra Coragyps sapiens, allí el cuerpo —marcado como vida sacrificable o insignificante por la guerra como aparato de poder político- es el centro de la escritura dramática, sobre él se componen las imágenes que dan cuenta de las relaciones míticas del texto, las "corrientes de acción y de pensamiento que llevan al hombre a comprenderse a sí mismo dentro de su mundo" (Ricoeur, 1983, p. 169); es decir, este cuerpo animal y las imágenes que se desprenden de él pueden traducirse como lecturas de tiempo que permiten aquí comprender ese estado-mundo en el que el hombre y la sociedad están inmersos, y el cual es necesario develar.

La primera imagen que plantea la obra es la del cadáver como deshecho, en ella los cuerpos son inscritos en un limbo humano/animal que los reduce a cosas, a simple materia; por ello, los cuerpos reducidos son representados mediante una iconografía macabra que presenta al cuerpo ya sea como una masa informe y descompuesta, como en el siguiente texto: "y si terminamos flotando en un río y nuestra descomposición se acelera, entonces nos hinchamos y, navegando por la corriente por varios días con sus noches, nos convertimos en masas putrefactas" (Vergara, 2013, p. 197), o como cuerpos irreconocibles, por ejemplo: "con el cuerpo hinchado, los brazos partidos, el vientre morado y una cara que no parece cara [...] literalmente. Reducido a la nada. Aniquilado. Vuelto una pura nada" (Vergara, 2013, pp. 191-192). Estas imágenes del hombre reducido a cuerpo animal y luego reducido a masa, a nada, son la representación de la desfiguración del sujeto en la sociedad, la ambigüedad del cuerpo corresponde al borramiento del individuo, de su identidad $\mathrm{y}$, por tanto, de su historia.

La segunda imagen que sobresale en la obra es la del cuerpo como resto, como fragmento, como trozo de carne; un sin número de pedazos de cuerpos esparcidos que evocan el todo que antes fue y que ahora aparece desfigurado, fragmentado. Tal como se puede observar en el siguiente parlamento:

Ulpiano: [...] Troncos. De cristiano. Ni más ni menos. Troncos. Eso es lo que son. Troncos. Troncos de cristiano. Decir cadáveres parece ambicioso [...] Cadáveres. Restos. Los restos humanos que bajan por aquí son precisamente eso, restos. Despojos. Sobras. A cuotas: cabeza, tronco, rodillas, y pies... Pedazos de la guerra (Vergara, 2013, p. 185)

Los restos que bajan por el río son la representación simbólica de la situación presente del hombre, representan "la fragmentación o estallido del individuo", un hombre roto, descentrado, falto de unicidad e identidad (Viviescas, 2006, p. 31). Y, de manera similar, la suma de troncos humanos que corren sin destino por el río son la representación de una sociedad fracturada, cortada en piezas y lanzada a la deriva. En este contexto, la imagen del cuerpo como resto en Coragyps sapiens se convierte en el vestigio de las masacres ocurridas en los ríos colombianos, y, por ende, se instala como presencia y como memoria: como el "resto orgánico que resiste, permanece, insiste y se obstina” (Giorgi, 2014, p. 203).

En esencia, esos troncos, estas piezas sin eje, son los despojos de lo que alguna vez fue considerado un cuerpo, un humano, una identidad, una historia de vida y una historia en común, una comunidad. Entonces, ¿cómo recuperar este cuerpo y la historia en común?, lo anterior teniendo en cuenta que, precisamente, lo que pretende el exterminio no es solamente "matar sino negar cualquier rastro de existencia a través de una enorme violencia. Enmudecer, acallar, desaparecer al otro, negarlo incluso como cadáver a través de su desmembración" (Vallejo, 2012 , p. 207). Frente a esto, la obra a la vez que insiste en el resto como memoria de una violencia extrema contra el cuerpo, también pone en discusión la reconstitución del cuerpo, ya que la persistencia en la partes inconexas o faltantes obliga a la imaginación a reconstruir el todo, el cuerpo del hombre como individuo y, al mismo tiempo, el cuerpo como comunidad. Para ello introduce una figura animal: el zopilote. 


\section{Lo animal como símbolo de revitalización}

El zopilote como figura simbólica de purificación es el eje en Coragyps sapiens; en esta dramaturgia, él es el símbolo que representa la recuperación de lo humano, la restauración de la humanidad en el hombre, una humanidad que, como se pudo observar anteriormente, está rota, perdida. Para Ulpiano, uno de los protagonistas de la obra, los zopilotes, como purificadores, son por naturaleza unos sanadores y unos seres de paz, pues ellos se encargan de limpiar la muerte y esterilizarlo todo, "tienen una capacidad única para eliminar bacterias y virus en la comida que ingieren" (Vergara, 2013, p. 183). El pensamiento de Ulpiano concuerda con la simbología del animal, la cual le concede el título de purificador porque reconoce su labor como "agente regenerador de las fuerzas vitales, que están contenidas en la descomposición orgánica y en los desperdicios de cualquier clase" (Chevalier, 1986, p. 205) y, en ese sentido, es "un ser sagrado protector de la vida” (De La Garza, 1995, p. 88), renovador y transformador vital.

Por lo anterior, Ulpiano admira al zopilote, se identifica con él, se piensa como él e incluso se podría decir que es un zopilote más, pues también ha asumido la labor de limpiar los desechos de la guerra al dedicarse a rescatar los cuerpos del río y ofrecérselos a los zopilotes para que ellos hagan su trabajo. Él describe a la sociedad animal del zopilote como una sociedad perfecta donde reina la paz y la muerte solo se da por procesos naturales, una sociedad que él afirma se debería imitar. Así:

Vuelan en grupos. Y se ayudan mutuamente para buscar comida. No se tragan todo. Comparten. Son solidarios. Hay quien debiera aprender de ellos. [...] Hace ya tiempo que perdieron las garras prensiles de otras aves rapaces. No pueden matar a sus presas. No matan. No pueden. Nunca. Nunca, nunca. El pico no tiene la forma ni la fuerza para desgarrar una presa recién muerta. Seres de paz. [...] Y por la noche, en familia, disfrutan jugando al final de una larga jornada. Incluso pueden desarrollar vínculos afectivos con ciertas personas a quienes acompañan y protegen durante largas caminatas. Benditos sean (Vergara, 2013, pp. 182-184).

Como resultado de toda esta idealización del zopilote, Ulpiano concibe también la posibilidad de una nueva especie, un híbrido humano animal, hombre y zopilote, especie que podría llamarse "ya no Homo sapiens sapiens sino, digamos, Chulo sapiens" (Vergara, 2013, p. 190), un zopilote con la capacidad de pensar. Este razonamiento es el que justifica el nombre de la obra: coragyps (el nombre de la familia del zopilote) y sapiens (el homínido que piensa).

De esta manera, la especie ideal sería la de un hombre zopilote que tuviese la capacidad de purificar este espacio-mundo repleto de muerte y transformarlo en vida, y que, al igual que el zopilote, tuviera el poder de "triunfar sobre la muerte terrena y transmutar la podredumbre en oro filosofal" (Chevalier, 1986, p. 225). Con esta idea, lo que el texto propone es otra concepción de hombre y de comunidad, una antioccidental, que promueva más un pensamiento ancestral preocupado por la convivencia con lo animal y la naturaleza, no con la separación entre lo natural y lo cultural o lo político, entre zoé y bios. Una sociedad que no promueva las exclusiones y que sea irreductible a lo humano, una que pueda dejar sin sustento a la máquina antropológica que produce cuerpos humanos como desecho, la máquina de la guerra.

\section{La alianza humano animal}

La primera gran metáfora de la obra habla de la necesidad de transformación del hombre y de la sociedad a través de una alianza humano animal, unión que permita reestablecer los lazos humanos y comunitarios en el país. Dicha metáfora plantea una evolución hacia un hombre zopilote capaz de digerir la muerte y transformarla en vida, un hombre capaz de ser un sanador de su comunidad, un purificador. La segunda gran metáfora inmersa en el texto es la de la reconstitución del hombre y la reconstrucción de la sociedad, esta es planteada, en primer lugar, a través de la idea de una responsabilidad conjunta en la que la labor de purificación no sea de unos pocos, sino de todos y cada uno en conjunto; para ello, Reina, la otra protagonista de la obra, se opone a la idea de Ulpiano de señalar enfáticamente la magnitud de las masacres mediante la acumulación de los cuerpos para que "detengan a la gente en su camino con su olor" (Vergara, 2013, p. 192), ella va más allá del mero signo de denuncia proponiendo una acción más significativa: que cada persona acoja al menos un muerto y lo haga suyo.

Reina: Necesitamos adoptar. Todos. Uno. [...] Todos. Al menos uno. Usted también. Hacerlos nuestros hijos. Digerir la muerte... Y regurgitarla. Esterilizarnos, purificarnos, alimentar a nuestros polluelos con muerte vomitada. Con amor profundo. Usted lo dijo, "Gallinazos sapiens." [...] Todos necesitamos al menos uno. (Mirando al público.) Ellos también. Al menos uno. Al menos. Sentir la textura de la carne en descomposición. Su olor. Así no los olvidamos. Los olores hermanan, nos hacen familia. Y la familia no se olvida. Que cada quién se haga cargo de un par o un trío. Aunque tres ya podría tal vez ser demasiado. Pero no si lo hacemos juntos (Vergara, 2013, pp. 201-203).

Como lo expresa el anterior parlamento, Reina propone un hermanamiento, una reunificación de esa sociedad que se encuentra fracturada, ello por medio del gesto de hacer propios a los muertos del conflicto armado, propone que esos cuerpos no sean asunto ajeno sino propio, para ella la responsabilidad debe ser compartida, al igual que el proceso de sanación. Todos los integrantes de la 
sociedad han de convertirse en "gallinazos sapiens", "La evolución tiene que ser nuestra. No de ellos. O de ellos y de nosotros a un tiempo y a la viceversa" (Vergara, 2013, p. 203). En segundo lugar, Reina propone que el fin de acoger a los muertos es para hacerlos suyos, llorarlos, darles un nombre y una sepultura; con esto plantea la necesidad de una reconstitución del cuerpo por medio del rito de la sepultura, la obligación de devolverle la humanidad a aquellos cuerpos que han sido exiliados del mundo humano al ser arrojados en piezas al río y nominados como cuerpo animal por la máquina de la guerra. Un aparato político que busca siempre borrar toda evidencia jurídica e histórica y "destruir los lazos de ese cuerpo con la comunidad, de hacer imposible la inscripción de ese cuerpo en la vida de la comunidad, en sus lenguajes, sus memorias, sus relatos" (Giorgi, 2014, p. 199).

$\mathrm{El}$ anterior planteamiento de Reina revela la existencia de un cuerpo simbólico fuera de sí, más allá del cuerpo físico, esto sería, según Butler (2006), una construcción del cuerpo dentro de "la esfera pública como un fenómeno social” (p. 52), un cuerpo entregado al mundo de los otros y reconocido por ellos, registrado en sus memorias y marcado con sus huellas. Ese sería el cuerpo a recuperar, ese cuerpo que posee una historia y hace parte de una comunidad. Por esto Reina insiste en la necesidad de hacer esa reconstrucción social a través del duelo y el rito de la sepultura.

Lo que se pretende es reconocer plenamente todas las vidas como vidas merecedoras de un duelo, romper con la distribución de las vidas valiosas y las vidas desechables, de las "personas" y las "no personas", para dar pie a un duelo conjunto y lamentar todas las muertes. Permitir el llanto y la memoria como un gesto de reconocimiento mutuo sin dar cabida a la exclusión, restituir a la persona, su identidad, su nombre y su historia. En consecuencia, el rito sepulcral se convierte, entonces, como parte de esta gran metáfora de reconstrucción social, en el símbolo de pasaje de un cuerpo reducido a cosa, a un cuerpo humano y, por tanto, a un cuerpo social, a un cuerpo en común, en comunidad. El duelo y el sepulcro se vuelven símbolos de una restitución de un espacio social vaciado, despojado de su simbólica de pertenencia, a un espacio en común, el espacio de la sociedad humana.

El último pasaje de la obra se constituye como el culmen de la gran metáfora de reconstrucción social; en él los dos protagonistas de la obra instan al público a adoptar cada uno un cuerpo, tomándolo físicamente de la escena, rompiendo por completo la "cuarta pared"3 y llevándolo

3 La "cuarta pared" es un concepto creado por Constantín Stanislavski para señalar el muro invisible que separa al público del actor y que mantiene el pacto de ficción de la obra. Por ello, cuando la cuarta pared cae, también cae el pacto de ficción y el público es impelido de diferentes maneras a hacer parte de la realidad-ficción de la obra, a sentirse involucrado prácticamente al nivel de un actor más. a los brazos de los espectadores, quienes con este gesto pueden experimentar, a manera de catarsis, el compromiso social con la reconstrucción y la labor de sanación que está por emprenderse. Reina acompaña el gesto de entrega de los cuerpos con una serie de parlamentos que arrojan al público a acoger los cuerpos como una forma simbólica del compromiso que cada asistente tendrá en la vida real. Veamos algunos de ellos:

Reina: (A alguien en el público.) Llévese uno. Es obvio que vino a eso [...] No se arrepienta. Eso la sana. Le juro. Todos necesitamos al menos uno. Aunque uno no es suficiente. Llévese otro. [...] Páseselo por el vientre, hágalo suyo, como si fuera su hijo. Es suyo. No lo niegue. Si hasta se le parece (Vergara, 2013, pp. 203-204).

Los anteriores textos involucran más activamente al público, de esta manera, él pasa de ser un simple espectador a ser parte de la acción y de la solución esbozada en la obra, él pasa a ser un agente de cambio en la simbólica de la obra, que lo impulsa no solo a acoger los muertos del conflicto como propios, sino a no hacer ninguna distinción entre ellos, pues su "parecido", su igualdad radica en "ser humano". Todos los muertos son parte de una misma sociedad, la humana.

Después de esta última acción, la obra termina con una imagen de liberación donde los personajes, ya convertidos en hombres zopilotes, se cortejan uno al otro, cantan, danzan y con algunos aleteos dejan la escena en una sensación de paz y retorno al orden natural, al equilibrio. Este final, en el que tanto los personajes como los espectadores sufren una liberación, una catarsis, plantea una poética y una simbólica que destaca la restauración de la vida sobre la muerte, la restauración de la naturaleza y del entramado social por medio de un hermanamiento y una responsabilidad conjunta de reconstrucción social.

\section{El mito de la renovación}

Los mitos y ritos de la renovación, estudiados ampliamente por Mircea Elliade, relatan la existencia de un tiempo cíclico en el que al final de un ciclo sigue el inicio de otro nuevo, una renovación de mundo. Tal renovación "es una recreación efectuada según el modelo de la cosmogonía" (Elliade, 2006, p. 48), aparece como respuesta a un problema de la existencia humana: el quebrantamiento del orden y la necesidad de volver a él. Respecto al modelo de cosmogonía, Coragyps sapiens encuentra un sustento bajo la cosmovisión ancestral andina regida por los principios de la "armonía". Una visión que Aedo (2015) llama cosmobiovisión para aclarar la diferencia con las concepciones occidentales de mundo, y que define como: "un modo de 'ver' y sobre todo un modo de pensar y sentir (pensasiento), de percibir e intuir, cuatro categorías filosóficas y cualidades subjetivas de la Pacha; contrarios que se complementan para formar al Cosmoser", una visión 
holística en la que todas las cosas forman una única unidad, el "todo" (p. 10).

Dentro de esta visión de mundo sobresalen en la obra un buen número de los principios de la "armonía", entre ellos: el de "identidad" que reza que "cada ser debe reconocer y respetar las diferencias", este se encuentra reflejado en el pensamiento de Ulpiano al explicar que la familia Cathartidae, a pesar de dividirse en diferentes especies, conviven en armonía, comparten el alimento y el espacio sin perturbar al otro. Coragyps atratus (cabecinegro), Cathartes aura (cabecirrojo), Cathartes burrovianus (cabeciamarilla), Sarcoramphus papa (rey de los gallinazos) y demás, "blanco, negro, rojo, amarillo y gris", conviven en la diferencia y se ayudan mutuamente.

El del "equilibrio", que expresa la idea de igualdad entre todos los seres, es quizá el más presente, ya que la obra insiste en señalar el desequilibrio promovido por unos seres que han dispuesto de las vidas de otros al considerarlas prescindibles. La ley del Ayni o principio de reciprocidad que plantea "la reproducción y redistribución de los excedentes de la economía colectiva” (Milla, 2004, p. 150); sin embargo, este principio no solo se refiere a la redistribución económica, incluye el intercambio del conocimiento, de la labor social, del apoyo espiritual, etc. Así, dentro de esta filosofía, son rechazados conceptos como el individualismo, la competencia y la ganancia, para ser acogidos otros como comunidad, colectividad y solidaridad.

En relación con el mito de renovación como respuesta al quebrantamiento del orden y la necesidad de volver a él, dos principios de la filosofía andina están muy presentes. El de la alternancia, que expresa que un movimiento sucede al otro, "después de la creación (Big Bang) le sigue la aniquilación (Big Crush), después del sístole le sigue el diástole, después de la vida le sigue la muerte, después del día le sigue la noche” (Aedo, 2015, p. 27); también el principio del eterno retorno, que formula el movimiento cíclico de la vida como una forma de expresión del tiempo, "donde todos los seres nacen, crecen, se reproducen, mueren para volver a nacer" (Campohermoso y Soliz 2015). Estos principios, tanto el de alternancia como el del eterno retorno están presentes en la obra gracias a la figura del zopilote y su trabajo de purificación, pues él contribuye a la reconstitución del orden natural de las cosas y al movimiento cíclico vital de la naturaleza comiéndose la muerte para engendrar vida.

Como se puede intuir gracias a la cosmovisión presente en Coragyps sapiens, lo que narra esta dramaturgia es un mito de renovación, al proponer una suerte de símbolos de transformación y un rito que involucra una acción conjunta de purificación y una promesa de estabilidad y fecundidad.

La obra reproduce el momento mítico "del pasaje del Caos a la Cosmogonía” (Elliade, 2001, p. 37), en ella, el espacio se transforma de una isla de terror abarrotada de cuerpos muertos a un espacio diáfano, en el que cada persona del público asume el rol de renovador y de consolidador de paz. El espacio del cuerpo, antes destinado a la parte, al desecho, el detritus, el resto, la sobra, lo corrupto y lo pútrido, es recompuesto para lograr una completitud y una plenitud. El espacio geográfico también se abre de un reducto al país, a la nación. Lo clandestino es sacado a la luz para airearse, limpiarse. La oscuridad ha dado paso a la luz, la inercia a la acción, el caos es suplantado por un nuevo nacimiento del orden.

Las acciones que suceden en la obra pueden interpretarse como los pasos del ritual de renovación; así, en primer lugar, la sala de teatro, e incluso el espacio íntimo de la lectura, se convierte en el sitio de encuentro, en el símbolo del "centro" como el lugar del pacto de participación del tiempo mítico y, en segundo lugar, se suceden una serie de acciones dramáticas que conforman el rito, a saber, "la restauración del caos primordial, la abolición del tiempo transcurrido y la repetición del acto cosmogónico" (Elliade, 2001, p. 38), lo que se puede detallar así:

- Regresión al caos o el establecimiento del "caos primordial" a través de la construcción de un espacio de muerte y caos en la obra. Ulpiano construye un reducto donde reina un caos de cuerpos que se descomponen y esperan la llegada de los zopilotes.

- La limpieza gracias a una inundación diluviana propiciada por una figura extraña a los protagonistas, una especie de hombre primitivo conocedor de la naturaleza y sus ciclos, personaje que encarna el conocimiento ancestral cósmico, como se puede apreciar en el siguiente texto:

Reina: [...] Pero el tipo me saludó. Me sonrió y me preguntó que si andaba buscando el nacimiento del río. Y yo le dije que sí y él me dijo que ya no había necesidad. Que él ya había estado allá. Que había abierto la llave, que esa era su labor. Y que la había abierto porque el río necesitaba limpiarse. Y limpiarnos. Llevarse toda la basura. Me pidió que nos cuidáramos. Que iba a haber inviernos largos y aguaceros e inundaciones porque había que limpiar la tierra. Pero que no nos preocupáramos — dijo- porque en su momento él volvía a subir a la cabecera y cerraba la llave. Luego empezó a caminar (Vergara, 2013, p. 195).

Este hombre que aparece desde lo profundo de la selva representa al ser mítico encargado del manejo del agua, el gran fontanero del mundo. Una especie de Yahvé andino que inicia el barrido del tiempo anterior para dar cabida a uno nuevo.

- La participación de Ulpiano y Reina en la restitución de la humanidad de un tronco rescatado del río al 
bautizarlo con el nombre de Carlos Antonio Buitrago, lo que representa el restablecimiento del principio de equilibrio, al plantear la restauración del espacio social de aquellos seres nominados inferiores, no valiosos o prescindibles; la restitución de su universo de pertenencia y la reconstrucción del cuerpo simbólico como forma de hermanamiento e inscripción subjetiva y comunitaria.

- La celebración de una clase de ceremonia comunal de acogimiento de la muerte al asumir como suyo por lo menos un muerto del conflicto armado colombiano. Celebración en la que cada uno de los participantes no solo se compromete con la protección del cuerpo, sino también a darle un nombre y una sepultura, acción simbólica que permite la purificación y la "anulación de los pecados y de las faltas del individuo y de la comunidad en su conjunto" (Elliade, 2001, p. 36). Tal es el sentido de las purificaciones rituales, darle término a un periodo de tiempo, pero, sobre todo, anular el tiempo transcurrido, la abolición de la "historia" (Elliade, 2001, p. 35), para poder dar paso al nuevo comienzo.

- Como en muchos de los ritos de renovación se da finalmente una hierogamia. Para este caso, una unión sagrada entre el hombre y el animal, la transformación de los personajes en hombre y mujer zopilote, lo que marca el nacimiento de un nuevo hombre y un nuevo mundo. Una unión sagrada que promete una renovación, "la estabilidad, la fecundidad y la prosperidad de todo el cosmos" (Elliade, 2006, p. 47).

En suma, como recreación del mito de renovación, las acciones de la obra siguen los pasos del ritual para trazar un camino que va del caos al nacimiento de un nuevo orden, esto mediante una alianza humano animal que da origen a una nueva especie, la Coragyps sapiens, el hombre zopilote. Especie que, como comunidad, será la encargada de recomponer el cuerpo social del país expiando sus culpas, acogiendo el pasado pero dejándolo atrás para entrar al nuevo mundo. Un mundo renovado, diáfano, gobernado por todas las fuerzas vitales de la naturaleza y regido por los principios de la "armonía".

\section{Conclusiones}

En Coragyps sapiens el zopilote dibuja un nuevo espacio, un espacio que se abre por encima del hombre mismo y rompe con el redil del animal, rompe con lo liminar de lo animal para crear una unión humano-animal, una alianza. El animal no funciona aquí bajo la orden antropogénica que divide y opone radicalmente al animal del humano, sino que, por el contrario, se configura como un retorno al origen, a lo natural, al vínculo inseparable, a la alianza, a la unidad. El animal no es el otro, tampoco el huésped, es parte, esencia y completitud. Hace parte de ese cuerpo que se denomina humano.
Esta nueva alianza humano-animal que reconoce una contigüidad intensa entre esa especie llamada Atratus y la Sapiens es la fórmula que posibilita el encontrar una salida al estancamiento, a la esterilidad del tiempo que transcurre solo para acumular, no solo restos, sino impotencias, frustraciones, rencores y odios en la sociedad colombiana. La propuesta de Vergara es una propuesta de reordenamiento del cuerpo social. La reconstitución de las víctimas que fueron "desmembradas del cuerpo social que las justificaba existencialmente" (Cardona, 2014, p. 581), la reconstrucción de ese cuerpo que por décadas ha estado partido en piezas, regado en los ríos, en los campos, en la selva y en las ciudades, y el nacimiento de una comunidad donde puedan ser reconocidas nuevamente las formas de lo humano, pero bajo el signo animal, para que este zurza las piezas creando un nuevo cuerpo que pueda albergar todos los cuerpos, aceptar la diferencia. Una sociedad sin muros y sin abismos.

De ahí que, como respuesta a la pregunta sobre la forma en la que el arte dramático puede contribuir a la reconstrucción del tejido social, Coragyps sapiens propone, a manera de metáfora, una tarea de reconstrucción social para el posconflicto, cumpliendo con una función determinante del arte según Molano (2015), la de "introducirle al mundo lo que no tiene: posibilidades, imaginar realidades, imaginar espacios nuevos, juegos, desafíos, exploraciones, experimentos, [...] y esto desde luego es concomitante con la noción de paz", y la necesidad de encontrar caminos que lleven a la reconstrucción del país. El texto de Vergara, podría decirse, invita a la "pedagogía de acción", ya que involucra el llamado a una acción conjunta de la toda la sociedad colombiana: la limpieza de la muerte y la purificación de la existencia. Esto mediante la acción de acoger esa muerte material y hacerla propia, dando nombre y tumba a todos los muertos, "vengan de donde vengan y sean quiénes sean” (Vergara, 2018).

Con el llamado a la reconstrucción social del cuerpo simbólico a través del duelo y la sepultura, Coragyps sapiens hace un llamado a la construcción de un mundo posible, a un cambio, a una renovación del pensamiento y a la acción. Convoca a los asistentes a crear lazos fraternales, romper barreras, imaginar y crear posibilidades de cambio futuro, una tarea que puede generar, como dice Vergara, "pequeños cambios micro políticos", cambios que son los que reconstruyen el tejido social desde su base: el individuo. Así, esta obra dramática, al igual que el arte en general, puede contribuir a fortalecer "el arraigo, la identidad, la convivencia, y los lazos de unión de las comunidades" (Arteta, 2017), y a creer en una visión de país más esperanzadora y reconciliadora como aporte a la construcción de la paz. 


\section{Referencias}

Aedo, J. (2015). El aprendizaje del cosmocer, el desarrollo del cosmoser y su aplicación al programa educativo. Recuperado de http:// yuraqaqaruna.blogspot.com.co/2015/06/cosmobiovision-andinoamazonico-y.html

Agamben, G. (2006). Lo abierto: el hombre y el animal. Buenos Aires: Adriana Hidalgo Editores.

Arteta, C. (2017). ¿Y si el arte y la cultura fueran las claves de la reconciliación en Colombia?. Recuperado de: http://www.semana.com/ nacion/articulo/el-arte-y-la-cultura-como-agentes-de-transformacion-y-reconciliacion-en-colombia/529466

Butler, J. (2006). Vida precaria. El poder del duelo y la violencia. Buenos Aires: Paidós.

Campohermoso, O. y Soliz, R. (2015). Lógica Aimara trivalente y cosmovisión andina. Revista Cuadernos, 56(2), pp. 89-97.

Cardona, J., 2014. Arte, ritual y masacre. Reflexión sobre la reconciliación en el posconflicto colombiano. Anuari del conflicto social, pp. 576-598.

Centro Nacional de Memoria Histórica. (2013). ¡Basta ya! Colombia. Memorias de guerra y dignidad. Bogotá: Imprenta Nacional.

Chevalier, J. (1986). Diccionario de los simbolos. Barcelona: Editorial Herder.

De la Garza, M. (1995). Aves sagradas de los mayas. Ciudad de México: UNAM.

Derrida, J. (2008). El animal que luego estoy si(gui)endo. Madrid: Editorial Trota.

Elliade, M. (2001). El mito del eterno retorno. Buenos Aires: Emecé Editores.

Elliade, M. (2006). Mito y Realidad. Barcelona: Editorial Kairós.
Fleisner, P. (2010). Hominización y animalización. Una genealogía de la diferenciación entre hombre y animal en el pensamiento agambeniano. Contrastes. Revista Internacional de Filosofia, 15, pp. 337-352.

Giorgi, G. (2014). Formas comunes. Animalidad, cultura, biopolitica. Buenos Aires: Eterna Cadencia.

Lamus, M. (2013). Dramaturgia colombiana contemporánea. Antología II. Bogotá: Ministerio de Cultura de Colombia.

Milla, C. (2004). Ayni: semiótica andina de los espacios sagrados. Lima: Amaru Wayra.

Molano, C. (2015). ¿Cuál es el papel del arte y la cultura en la construcción de la paz?. Desde Abajo, 25 abril.

Ricoeur, P. (1983). Finitud y Culpabilidad. Madrid: Taurus.

Rodríguez, J. (2015). Puerto Berrío: entre un cementerio de agua y una creciente de lágrimas. Dimensiones sociales, politicas y culturales de las prácticas funerarias en el conflicto armado. (Tesis de maestría). Bogotá, Universidad Nacional de Colombia.

Sahua, J. (2007). La doctrina secreta de los incas. Huancayo. Perú: CAESAN.

Vallejo, A. (2012). Escrituras del cuerpo en el teatro colombiano contemporáneo. En: Pensar el teatro. Becas de investigación teatral. Bogotá: Ministerio de Cultura de Colombia, pp. 145-342.

Vergara, F. (2013). Coragyps sapiens. En: Dramaturgia colombiana contemporánea. Antología II. Bogotá: Ministerio de cultura de Colombia, pp. 179-205.

Vergara, F. (2018). La creación de Coragyps Sapiens. [Entrevista].

Viviescas, V. (2006). Dramaturgia colombiana: el hombre roto. Recuperado de http://www.casa.co.cu/publicaciones/revistaconjunto/141/victorviviescas.htm 